\title{
Effect of Temperature Fluctuations on the Bearing Capacity of Cold In-Depth Recycled Pavements
}

\author{
Andreas Loizos and Vasilis Papavasiliou *
}

Citation: Loizos, A.; Papavasiliou, V. Effect of Temperature Fluctuations on the Bearing Capacity of Cold In-Depth Recycled Pavements. Sustainability 2022, 14, 426. https: / / doi.org/10.3390/su14010426

Academic Editors: Dimitrios

G. Goulias and Marco Bassani

Received: 15 November 2021

Accepted: 27 December 2021

Published: 31 December 2021

Publisher's Note: MDPI stays neutral with regard to jurisdictional claims in published maps and institutional affiliations.

Copyright: () 2021 by the authors. Licensee MDPI, Basel, Switzerland. This article is an open access article distributed under the terms and conditions of the Creative Commons Attribution (CC BY) license (https:// creativecommons.org/licenses/by/ $4.0 /)$.
Laboratory of Pavement Engineering, National Technical University of Athens (NTUA), 15773 Athens, Greece; aloizos@central.ntua.gr

* Correspondence: vpapavas@central.ntua.gr; Tel.: +30-2107721279

\begin{abstract}
This study investigates the influence of the temperature fluctuations on the bearing capacity of cold in-depth recycled (CIR) pavements stabilized with foamed asphalt (FA). Aiming to achieve this goal, non-destructive testing was conducted during mild and high temperatures on a highway CIR pavement, utilizing mainly the FWD device. The back-calculated moduli values were utilized to estimate the strain values within the body of the pavement, while the strains induced using the FWD device were measured with a fiber optic sensors (FOS) system. Moreover, data from the fatigue behavior of the layer materials was also considered. The results of the related analysis indicate that for every $1^{\circ} \mathrm{C}$ temperature increase within the body of the AC overlay, an approximately $5.7 \%$ increase of the critical tensile strain is expected. Moreover, for every $1{ }^{\circ} \mathrm{C}$ temperature increase within the body of the FA layer, an approximately $1.8 \%$ increase of the tensile strain at the bottom of the FA layer is expected. The new constructed layers, i.e., asphalt concrete (AC) and FA, sustain much more damage at high temperatures. This was more evident in the upper layer, i.e., the AC overlay.
\end{abstract}

Keywords: temperature fluctuations; foamed asphalt; non-destructive testing; fiber optic sensors

\section{Introduction}

Aiming to reduce energy requirements, emissions, and environmental impact, multiple low-energy technologies have been introduced, focusing on constructing/rehabilitating sustainable pavements.

The definition of a "sustainable" pavement is not unique considering that each project has different characteristics, such as available local materials, climate conditions, etc. Pavement's sustainability is only one small part of the transportation infrastructure system, and consequently, any implementation of improvements towards the sustainable characteristics of a pavement should be done considering the transportation infrastructure system and all the other systems with which pavement interact [1]. As issued by the World Commission on Environment and Development (WCED) in 1987: "Sustainable development is development that meets the needs of the present without compromising the ability of future generations to meet their own needs." Sustainability is also described as a quality that reflects the balance of three components, i.e., economic, environmental, and social impacts. The importance and consideration of each factor is depended on the characteristics, location, materials, and constraints of each project.

In order to achieve the abovementioned goal of sustainable pavements, asphalt mixtures produced at low temperatures were introduced [2,3]. However, these mixtures can only be successful if the mechanical properties and the durability of the pavement structure could be equivalent to the conventional pavements with hot-produced asphalt mixtures. Consequently, aspects like mechanical properties of the end product play an important role $[4,5]$.

Cold in-depth recycling (CIR) meets the criteria of sustainable pavements by introducing a "zero waste" approach to the rehabilitation of distressed pavement structures 
where the existing pavement material is reprocessed in place, avoiding any transportation. Moreover, the need for additional new pavement materials is minimized [6].

Multiple research papers concerning mix design procedures, comparison of different CIR technologies, as well as performance and construction aspects have been published, as shown, for example, in [7]. During the last decades, CIR technology utilizing foamed asphalt (FA) has gained popularity [8] due to the efficient use of a variety of existing materials, such as crushed stone, gravels, and reclaimed asphalt pavement (RAP). Other benefits include relatively short construction period and improved traffic safety.

CIR technique with FA is traditionally used for base or subbase construction on roads with low or medium traffic. However, it has also been used on heavily trafficked roads/highways to stabilize base courses [9]. Other studies have shown that the FA material can be applied to heavy-trafficked pavements applications if designed, installed, and cured properly $[10,11]$.

Due to the presence of mixing moisture, a curing period is required for FA mixes both for testing in the laboratory and in the field before being subjected to traffic. Consequently, the early-life strength represents the most critical period. Information concerning the earlylife performance of CIR heavily trafficked pavements with FA using non-destructive tests (NDTs) as well as laboratory estimated fatigue characteristics of the FA and asphalt concrete (AC) materials has been published, among others, in [12]. Analysis results highlight the importance of the AC layer thickness laid on top of the FA layer for the structural adequacy of the CIR pavement.

The temperature susceptibility of the FA materials has been evaluated in the laboratory and in situ $[5,13,14]$, indicating that the FA modulus is less sensitive to temperature changes in comparison to a typical, dense-graded AC mixture. However, this finding does not provide information concerning the influence of pavement temperature on the field performance of CIR pavements using FA with a relatively thick AC overlay. More field data information is necessary to investigate potential changes of the structural adequacy of these pavements and therefore the sustainability of the aforementioned CIR technique due to pavement temperature variations.

In order to contribute towards the above-mentioned issue, a field experiment was carried out by the Laboratory of Pavement Engineering of the National University of Athens (NTUA) along a trial section of a heavily trafficked Greek motorway (approximately 1.2 million ESALs per year), which is also an LTPP site. In-situ NDTs, including FWD measurements, were carried out during two periods, i.e., during early spring and early summer, at mild and high temperatures, respectively. Based on the field-collected data, back-analysis was performed to estimate the moduli of the pavement layer materials. Calculations of strains were also carried out at critical positions within the body of the pavement. The analysis results were preliminarily evaluated, utilizing the outcome of the analysis (strains) of a road experiment conducted on CIR pavements instrumented with a fiber optic sensors (FOS) system [15]. The expected deterioration of the materials was estimated with laboratory-estimated fatigue analysis.

Most of the researches deal with the temperature sensitivity of the CIR material, considering the material as an individual pavement layer. The present research aims to fill the gap between this approach and the consideration of the CIR layer as a layer in conjunction and interaction with a relatively thick AC overlay of a heavy-duty pavement structure. The calculation of moduli and strains was conducted, utilizing relatively simple assumptions and software, and the results were preliminarily evaluated, utilizing the outcome of other experimental studies. An outcome of the present analysis is the estimation of the rate of change of critical strains with respect to temperature fluctuations. A rough estimation of the rate of damage was achieved, utilizing the results laboratory fatigue tests (ITFT) for AC and FA materials.

The main findings and conclusions of the data analysis are presented and discussed in the present study. 


\section{Test Sites-Recycled Material and Data Collection}

\subsection{Foamed Asphalt Mix Design}

Foamed asphalt (FA) mix design was conducted to determine the application rates for foamed bitumen and active filler (cement) to achieve optimal strengths and to estimate the strength characteristics of the material. For this reason, tests were performed on different blends of material recovered from test pits. The indirect tensile strength (ITS), tensile strength retained (TSR), and unconfined compressive strength (UCS) of the treated material were determined. A range of foamed bitumen contents were tested to identify the optimum application rate, indicated by the highest ITS for each blend, using 100-mm Marshallcompacted for further testing and for ITS, TSR, and UCS determination using 150-mm diameter (120-mm high) briquettes (wet and equilibrium (Equ.) moisture content). A summary of the abovementioned results (average values) is presented in Table 1. According to the mix design, $2.25 \%$ foamed asphalt and $1 \%$ cement was used in the stabilized material. The decision to introduce $1 \%$ cement was based on the improvement in the achieved soaked (wet)-strength briquettes (dry, wet).

Table 1. FA mix design tests.

\begin{tabular}{|c|c|c|c|c|c|c|c|c|}
\hline \multicolumn{2}{|c|}{ Blend Components } & \multicolumn{2}{|c|}{ ITS $\Phi 100$ mm } & TSR & \multicolumn{2}{|c|}{ ITS $\Phi 150$ mm } & \multirow{2}{*}{$\begin{array}{c}\text { TSR } \\
(\%)\end{array}$} & \multirow{3}{*}{$\begin{array}{c}\text { UCS } \Phi 150 \mathrm{~mm} \\
(\mathrm{kPa}) \\
\text { Equ. }\end{array}$} \\
\hline \multicolumn{2}{|c|}{$(\%)$} & \multicolumn{2}{|c|}{$(\mathbf{k P a})$} & $(\%)$ & \multicolumn{2}{|c|}{$(\mathbf{k P a})$} & & \\
\hline RAP & Granular & Dry & Wet & & Equ. & Wet & & \\
\hline 75 & 25 & 318 & 238 & 75 & 301 & 237 & 79 & 1900 \\
\hline 50 & 50 & 354 & 277 & 80 & 279 & 252 & 90 & 2400 \\
\hline
\end{tabular}

From the laboratory tests, an average resilient modulus value of $2020 \mathrm{MPa}$ was determined.

\subsection{Data Collection}

The cross-section of the CIR pavement is presented in Figure 1.

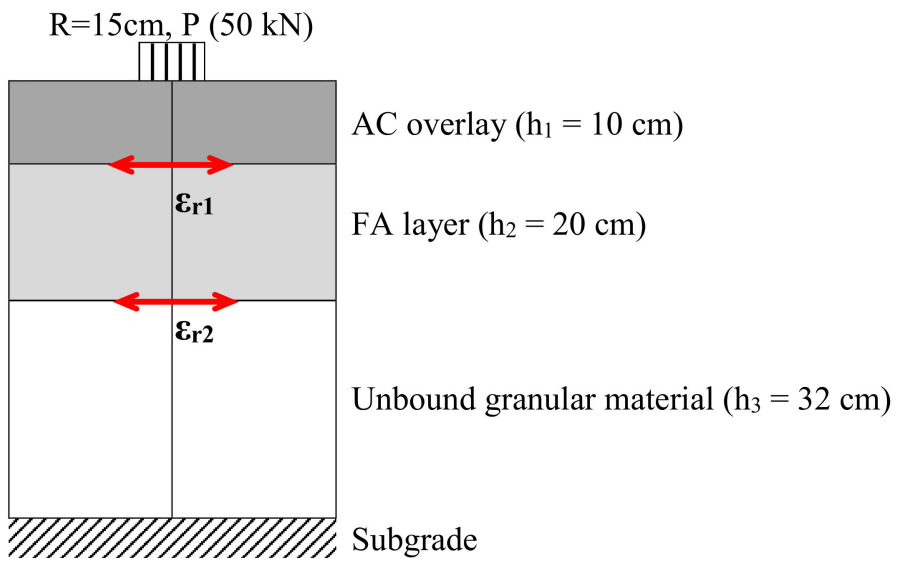

Figure 1. Pavement model (cross-section).

The NDTs utilizing the FWD device were conducted on the right wheel path of the heavily trafficked (right) lane at five test points on a 150-m long trial section. The applied FWD load was 50-kN load. The FWD generates a load pulse by dropping a weight on a loading plate, as shown in Figure 2. The peaks of the vertical deflections were measured at the center of the loading plate and at several radial positions $(200,300,450,600,900,1200$, 1500 , and $1800 \mathrm{~mm}$ ) by a series of 9 deflection sensors. 


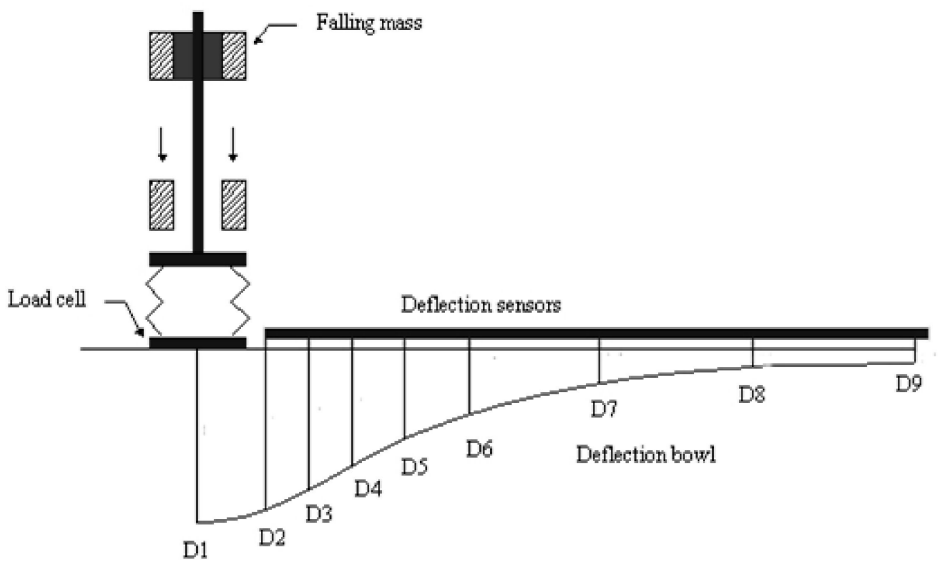

Figure 2. FWD sensors instrumentation.

The thicknesses of the pavement layers, i.e., the AC overlay and the FA layer, were derived from cores extracted from the pavement, while the thickness of the unbound granular material beneath the FA layer was estimated from geophysical data collected with the ground penetrating radar (GPR) device and processed with proper software [16]. The thickness of AC and FA layer was on average $10 \mathrm{~cm}$ and $20 \mathrm{~cm}$, respectively, while the average thickness of the unbound granular material was $32 \mathrm{~cm}$.

The FWD tests were performed for two different temperature periods, i.e., March and June, aiming to investigate differences of the in-situ behavior of the CIR pavement. For each period, the temperature in the body of the AC and the FA layers was measured during the FWD surveys.

For period 1 (March), the average temperature within the AC layers body was $16.6^{\circ} \mathrm{C}$ and $17.4^{\circ} \mathrm{C}$, while for the recycled base, it was $14.7^{\circ} \mathrm{C}$ and $16.2^{\circ} \mathrm{C}$ (mild temperatures). For period 2 (June), the average temperature within the AC layers body was $28.1^{\circ} \mathrm{C}$ and $33.3^{\circ} \mathrm{C}$, while for the recycled base, it was $28.5^{\circ} \mathrm{C}$ and $29.7^{\circ} \mathrm{C}$ (high temperatures).

During the period of measurements, the pavement was opened to traffic for approximately seven years. It was assumed that traffic loads during the short time period between the two measurement periods (March and June) did not significantly influence the structural condition of the CIR pavement.

\section{Data Analysis and Results}

\subsection{Back-Analysis}

Back-analysis was undertaken using MODCOMP software [17]. The cross-section of the CIR pavement is presented in Figure 1.

MODCOMP software is an internationally accepted back-analysis software that falls in the iterative search method. This method is based on the back-calculation program making repeated calls to an elastic layer subroutine to match the measured to calculated deflections. The iteration process stops when the measured and calculated deflections are within a tolerance level or when the maximum number of iterations is reached [18].

It is well accepted that the accuracy of FWD back-calculation is a problem and challenge. The question "How accurate are the back-calculated layer moduli from measured deflection basins?" is the most difficult question to be answered. Nevertheless, many researchers recommended the use of MODCOMP for back-calculating elastic layer moduli. It was found to result in reasonable solutions in over $90 \%$ of the initial study sections [19].

The characteristic back-calculated moduli (median values) were used for further analysis without correction to a reference temperature.

The AC back-calculated moduli were $12,800 \mathrm{MPa}$ to $7500 \mathrm{MPa}$ for temperatures $17^{\circ} \mathrm{C}$ to $33{ }^{\circ} \mathrm{C}$. The FA moduli values were $3160 \mathrm{MPa}$ to $1560 \mathrm{MPa}$ for temperatures $15^{\circ} \mathrm{C}$ to $30{ }^{\circ} \mathrm{C}$. The back-analysis results, i.e., the AC and FA moduli, with respect to the measured temperature, are presented in Figure 3. 


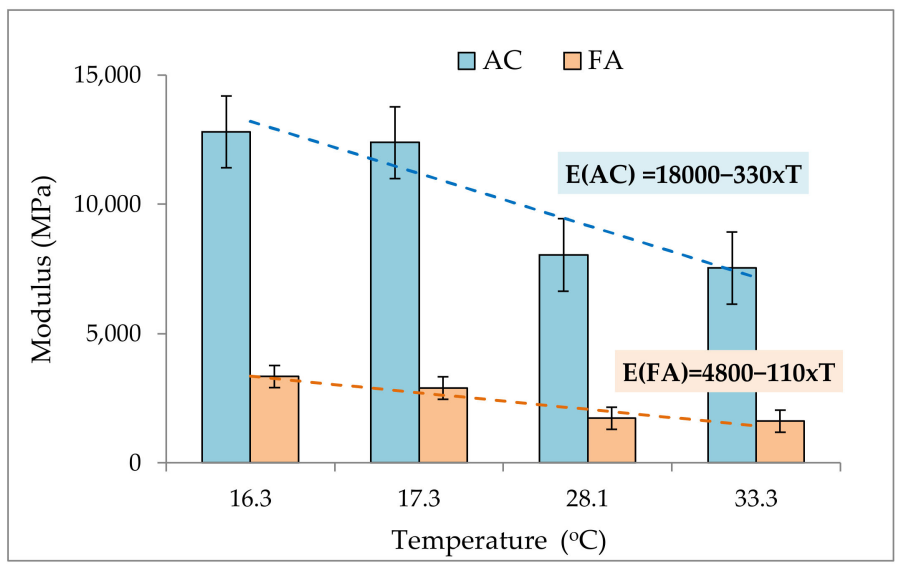

Figure 3. Back-calculated moduli.

As it can be seen, the AC moduli were much higher than the FA ones. Considering the slopes of the trend lines, the reduction of the modulus with respect to the temperature was approximately three times faster for the AC material. Therefore, it can be concluded that the FA material is less sensitive to temperature changes than the AC material. The above is also confirmed by similar results from indirect tensile stiffness modulus (ITSM) tests on laboratory produced FA and AC specimens [20].

\subsection{Calculation of Strains}

The pavement layer thicknesses and the back-calculated moduli were used for the forward calculation of the strains, using linear elastic analysis [21]. It should be mentioned that FA material often exhibits stress-dependent behavior. However, considering the in-situ linear elastic behavior of the FA material [20], the horizontal (tensile) strains at the bottom of the AC overlay $\left(\varepsilon_{\mathrm{r} 1}\right)$ and the FA layer $\left(\varepsilon_{\mathrm{r} 2}\right)$ as well were calculated using a multi-layer linear elastic analysis. A 50-kN single wheel load was used (in accordance with the load used during the FWD survey) with a $150-\mathrm{mm}$ radius.

In the case of flexible pavements, the critical against fatigue tensile strain is located at the bottom of the asphalt layer [22]. Considering that, in the case of CIR pavements, the location of the critical strain is not clear [23], in the present research work, the critical location in the body of the CIR pavement was investigated.

The outcome of the analysis, i.e., calculated strains in the body of the FA layer for the four measured temperatures, are presented in Figure 4.

As it can be seen, the most critical locations are found at the bottom and the top of the FA layer (Figure 1), confirming past investigations [24].

The strains at the top of the FA layer $\left(\varepsilon_{\mathrm{r} 1}\right)$ were 61 microns to 78 microns for temperatures $17{ }^{\circ} \mathrm{C}$ to $33{ }^{\circ} \mathrm{C}$. The strains at the bottom of the FA layer $\left(\varepsilon_{\mathrm{r} 2}\right)$ were 39 microns to 74 microns for temperatures $15^{\circ} \mathrm{C}$ to $30^{\circ} \mathrm{C}$.

The critical tensile strains $\varepsilon_{\mathrm{r} 1}$ and $\varepsilon_{\mathrm{r} 2}$, with respect to the measured temperature, are presented in Figure 5.

As it can be seen, the strains at the bottom of the FA layer $\left(\varepsilon_{\mathrm{r} 2}\right)$ were higher than the strains at the top of the FA layer $\left(\varepsilon_{\mathrm{r} 1}\right)$. Moreover, considering the slopes, it can be concluded that the strains induced at the bottom of the FA layer were less sensitive to temperature changes in comparison to the strains at the interface between AC overlay and FA layer.

The percentage difference of the calculated tensile strains from the lower value (induced at lower temperature), i.e., $\Delta \varepsilon_{\mathrm{r} 1}$ and $\Delta \varepsilon_{\mathrm{r} 2}$, with respect to the temperature difference $\Delta(\mathrm{T})$, is presented in Figure 6. 


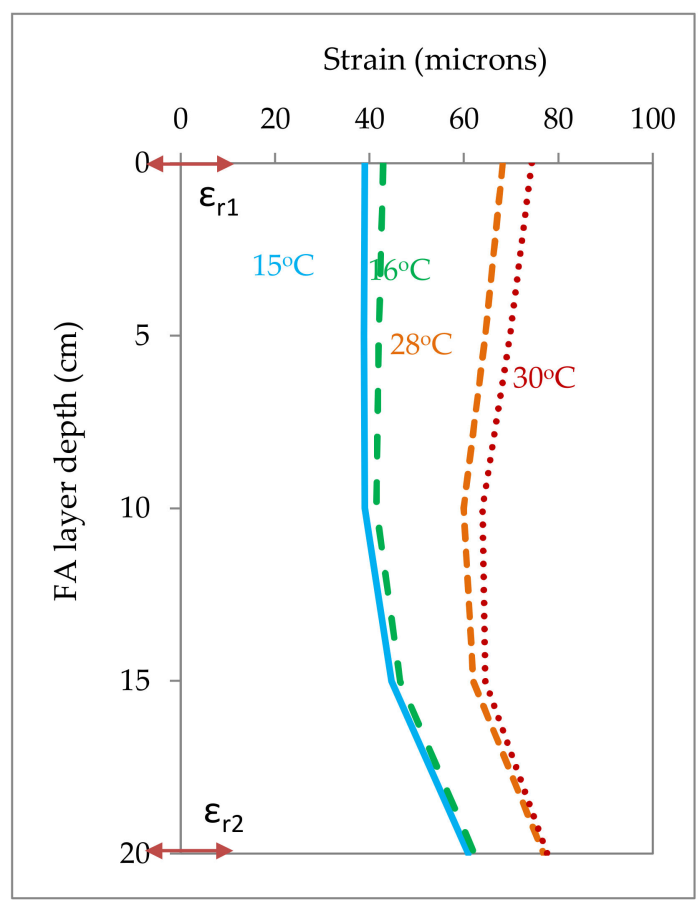

Figure 4. Calculated tensile strains in the body of the FA layer.

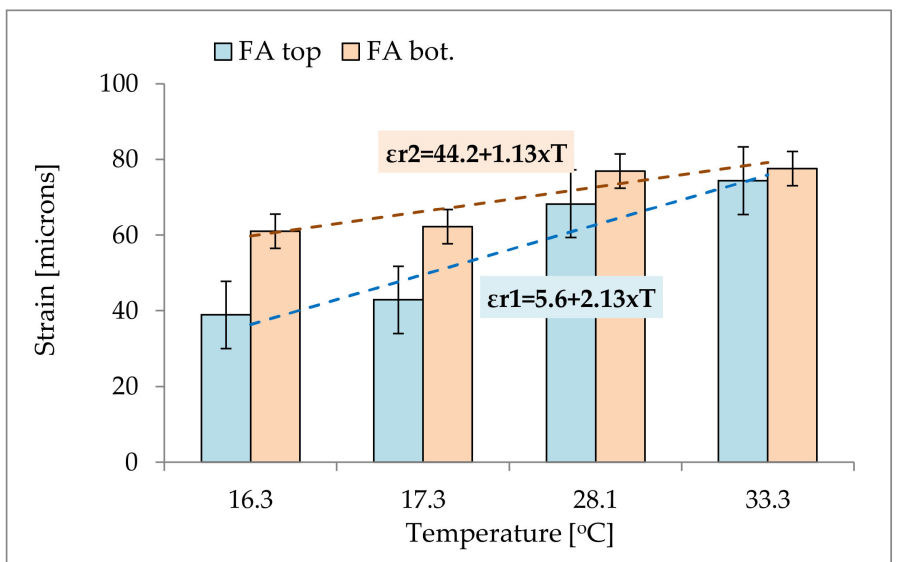

Figure 5. Critical tensile strains.

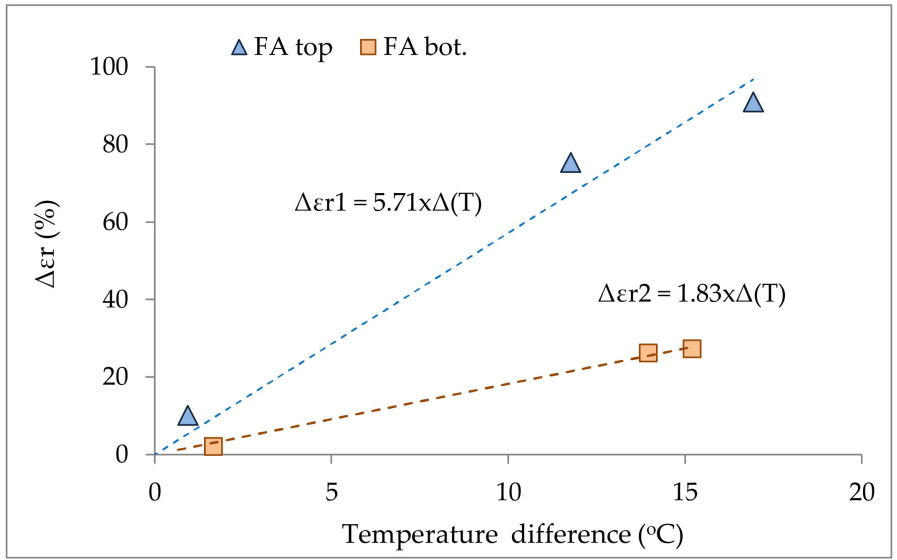

Figure 6. Tensile strain differences vs. temperature difference. 
It can be seen that, for every $1{ }^{\circ} \mathrm{C}$ temperature increase within the body of the $\mathrm{AC}$ overlay, an approximately $5.7 \%$ increase of the tensile strain at the interface between $\mathrm{AC}$ overlay and FA layer is expected. Moreover, for every $1{ }^{\circ} \mathrm{C}$ temperature increase within the body of the FA layer, an approximately $1.8 \%$ increase of the tensile strain at the bottom of the FA layer is expected (Equation (1)).

$$
\Delta \varepsilon_{r 2}=1.83 \times \Delta(T)
$$

As previously mentioned, due to the limited set of data, the above considerations are indicative only. Nevertheless, Equation (1) was evaluated using the analysis results (strains) of a road experiment presented in [15].

This road experiment was conducted at four test sites of two heavily trafficked motorways, rehabilitated using the CIR technique with FA. Two types of CIR pavements were considered in relation with the different types of "soil support," i.e., the remaining layer beneath the FA layer, i.e., unbound granular layer (test sites S1 and S2), or cement bound material (CBM) layer (test sites S3 and S4).

Strain measurements using FWD load were carried out at the bottom of the FA layer, with a fiber optic sensors (FOS) system [24]. In order to achieve this, strain sensors were instrumented in the laboratory to specific locations of cores, previously drilled from the pavements. The cores with the sensors were installed in the core hole, utilizing epoxy to secure them (see Figure 7).
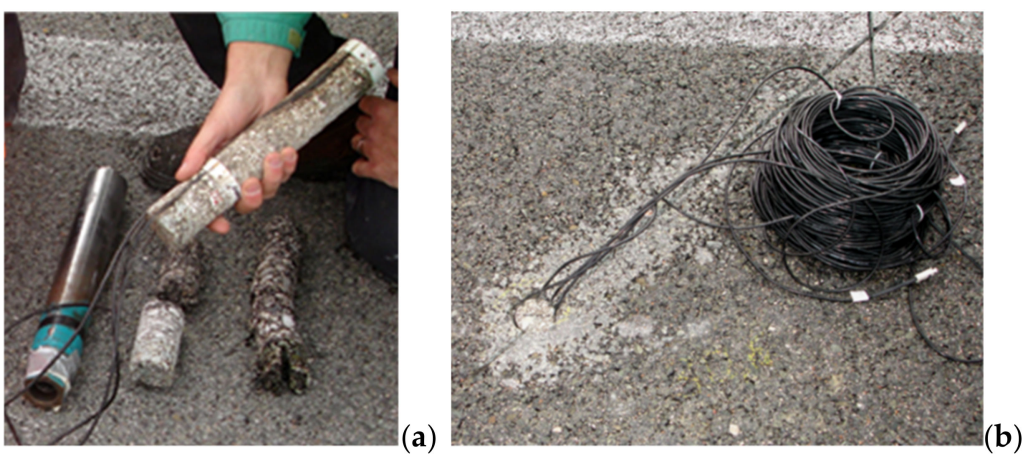

Figure 7. FOS installation. (a) Cores with sensors. (b) Sensors installed in pavement.

For estimation of the layer's moduli, back-analysis was performed with ELMOD software [25]. The calculation of strains was carried out with Finite Element (FE) linear analysis. For these calculations, a $65-\mathrm{kN}$ single wheel load with a $15-\mathrm{cm}$ radius was considered. That load was higher than the standard load level (50 kN) used during the FWD testing of the present investigation. However, considering the outcome of previous research [26], similar strain analysis results, i.e., maximum tensile strains, are expected when using moduli obtained from different FWD load levels.

FOS strains were measured through FWD loading $(65 \mathrm{kN})$ at two different temperature periods, i.e., winter and spring. For winter, the average temperature in the body of the FA layer was $16{ }^{\circ} \mathrm{C}$ (mild temperature), while for spring, it was $23^{\circ} \mathrm{C}$ (medium temperature). Figure 8 illustrates the measured $\left(\varepsilon_{\mathrm{m}}\right)$ and calculated $\left(\varepsilon_{\mathrm{c}}\right)$ strains at the bottom of the FA layer.

It can be seen that the calculated strain values were in all cases higher than the measured ones. Considering the different types of the CIR pavements and the temperatures as well, the calculated strains were 2 to 2.2 times higher than the measured ones with exception of the test sites S3 and S4 (with CBM beneath the FA) at mild temperatures (four times higher). 


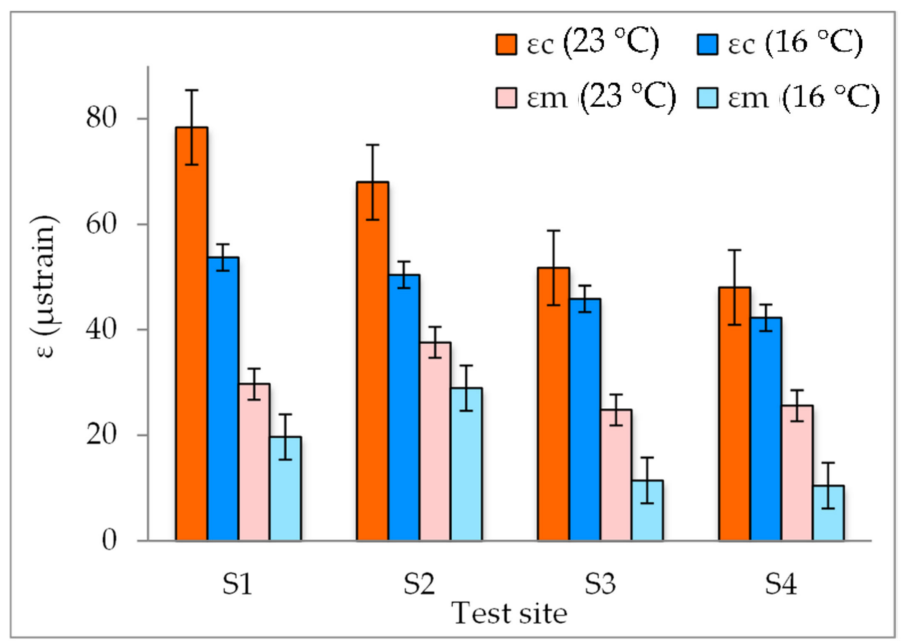

Figure 8. Calculated $\left(\varepsilon_{\mathrm{c}}\right)$ vs. measured $\left(\varepsilon_{\mathrm{m}}\right)$ tensile strains at the bottom of the FA layer [15].

The percentage increase of the strains from $16{ }^{\circ} \mathrm{C}$ to $23{ }^{\circ} \mathrm{C}$ was approximately $40 \%$ in the case of test sites S1 and S2 (with unbound granular material beneath the FA) regardless of the estimation method (calculations-measurements). However, in the case of test sites S3 and S4 (with CBM beneath the FA), the strain differences were $13 \%$ and $130 \%$ for the calculated and measured strains, respectively.

Despite differences in the conditions and the data analysis tools of the two experiments, i.e., FWD load, CIR pavement type (test sites S3 and S4), measured strains with FOS, backanalysis, as well as forward analysis method/software, the tensile strains at medium temperature $\left(23^{\circ} \mathrm{C}\right)$ were predicted using Equation (1). In order to do this, the measured and calculated strains at mild temperature $\left(16^{\circ} \mathrm{C}\right)$ were used for the analysis.

The comparison results of the measured strains $\left(\varepsilon_{\mathrm{m}}\right)$ versus the related predicted strains using Equation (1) $\left(\varepsilon_{\mathrm{m}(1)}\right)$ as well as the calculated strains $\left(\varepsilon_{\mathrm{c}}\right)$ versus the related predicted strains using Equation (1) $\left(\varepsilon_{\mathrm{c}(1)}\right)$ are presented in Figure 9. The percentage differences of the measured strains ranged from $13 \%$ to $54 \%$, with better approximation of the predicted strains for the CIR with unbound granular layer beneath the FA layer (test sites S1 and S2). The percentage differences of the calculated strains ranged from $0 \%$ to $23 \%$, with better approximation of the predicted strains for the CIR with CBM layer beneath the FA layer (test sites S3 and S4).

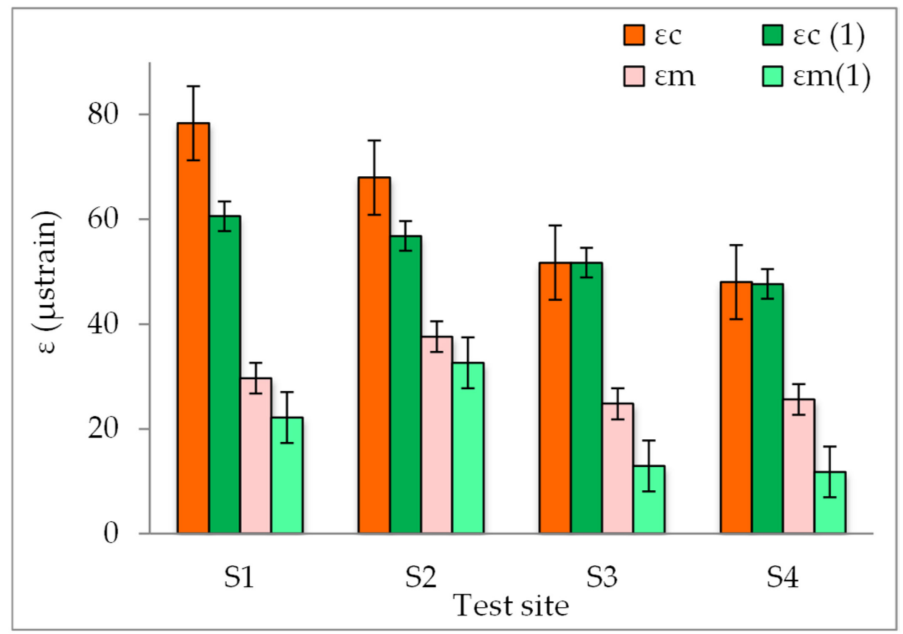

Figure 9. Measured/calculated strains at $23{ }^{\circ} \mathrm{C}$ vs. predicted from measurements at $16{ }^{\circ} \mathrm{C}$.

Notwithstanding the limited set of data, there is an indication that the calculated tensile strain at the bottom of the FA layer can be satisfactorily predicted at higher temperatures 
using Equation (1) regardless of the conditions of the experiment. However, this needs confirmation with more data.

\section{Fatigue Characteristics and Analysis}

\subsection{Fatigue Behavior of FA Material}

The fatigue behavior of the FA material was estimated on laboratory-compacted Marshall-specimens with the indirect tensile fatigue test (ITFT) [27]. Due to the different in-situ stress/strain conditions, shift factors need to be applied to use them for fieldperformance prediction [28]. Nevertheless, considering that these test results are not used for pavement structural evaluation, according to the international practice, laboratorydetermined fatigue curves are related with the fatigue in the field considering mainly the slope of the fatigue line.

Specimens were compacted and tested with FA material (with 3\% foamed bitumen and $1 \%$ cement) taken during construction. The specimens were cured for $72 \mathrm{~h}$ at $40{ }^{\circ} \mathrm{C}$ and at ambient temperature $\left(23-25^{\circ} \mathrm{C}\right)$ for six months in order to simulate the in-situ curing of the FA material [29].

The fatigue characteristics of the FA material are expressed by Equation (2).

$$
N_{F A}=a \times e_{r 2}{ }^{b}
$$

where $N_{F A}$ : cycles to failure, $e_{r 2}$ : maximum tensile strain, and $a$, b: coefficients $\left(a=6.7 \times 10^{16}\right.$, $\mathrm{b}=-5.8)$.

\subsection{Fatigue Characteristics of AC Overlay Material}

A laboratory fatigue test was carried out on dense graded AC mixes. The fatigue characteristics of the $\mathrm{AC}$ material are expressed by Equation (3).

$$
N_{A C}=c_{1} \times e_{r 1}{ }^{c 2}
$$

where $N_{A C}$ : cycles to failure, $e_{r 1}$ : maximum tensile strain, and $c_{1}, c_{2}$ : coefficients $\left(c_{1}=1.116 \times 10^{17}\right.$, $\left.c_{2}=-4.78\right)$.

The fatigue laws are presented in Figure 10 (code "AC": dotted line, code "FA": continuous line). According to the position of the fatigue lines, better performance of the AC material is expected, as also referenced in [12].

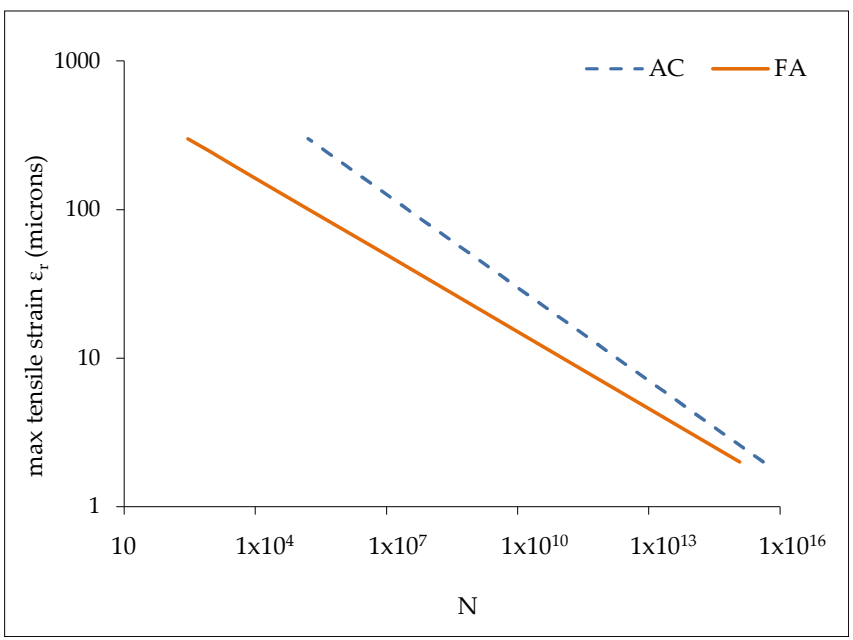

Figure 10. Fatigue characteristics of the FA and the AC materials. 


\subsection{Fatigue Analysis Results}

In order to achieve a rough estimation of the rate of fatigue damage of the CIR pavement with respect to temperature fluctuations, the results laboratory fatigue tests (ITFT) for AC and FA materials were utilized.

Using the fatigue laws presented in Equations (2) and (3), the cycles to failure were calculated for the FA and AC materials, respectively. The analysis results, i.e., the allowable $50-\mathrm{kN}$ load repetitions $\mathrm{N}_{\mathrm{FA}}$ and $\mathrm{N}_{\mathrm{AC}}$, with respect to the measured temperature, are presented in Figures 11 and 12, respectively.

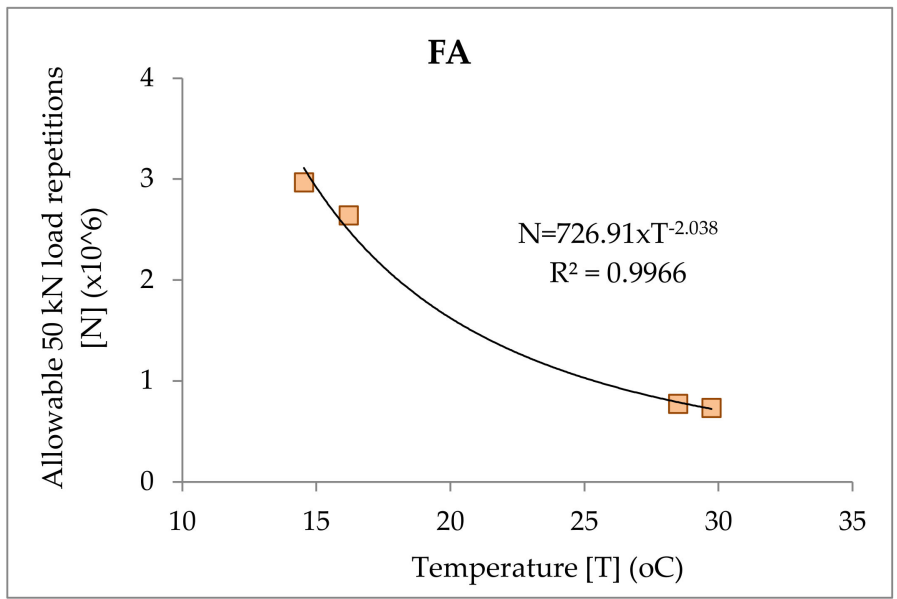

Figure 11. Allowable 50-kN load repetitions of the FA material.

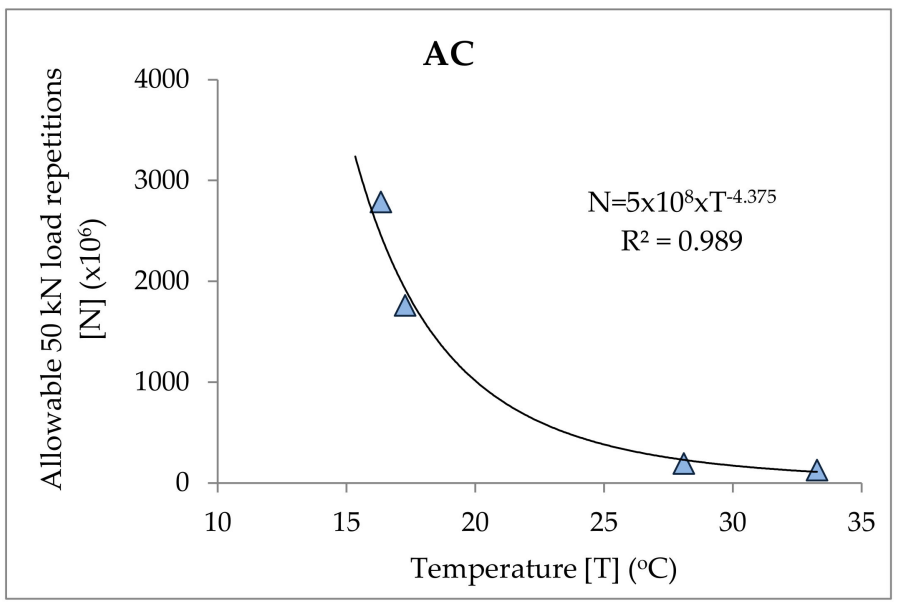

Figure 12. Allowable $50-\mathrm{kN}$ load repetitions of the AC material.

As expected, the allowable load repetitions of the $A C$ material $\left(\mathrm{N}_{\mathrm{AC}}\right)$ were much more than the allowable load repetitions of the FA material $\left(\mathrm{N}_{\mathrm{FA}}\right)$. At mild temperatures $\left(15^{\circ} \mathrm{C}\right.$ to $17{ }^{\circ} \mathrm{C}$ ), the rate $\mathrm{N}_{\mathrm{AC}} / \mathrm{N}_{\mathrm{FA}}$ was ranged from 667 to 939 . At high temperatures $\left(30{ }^{\circ} \mathrm{C}\right.$ to $33{ }^{\circ} \mathrm{C}$ ), the rate $\mathrm{N}_{\mathrm{AC}} / \mathrm{N}_{\mathrm{FA}}$ was ranged from 173 to 247 . This indicates that $\mathrm{FA}$ is more susceptible to fatigue cracking than the AC.

Considering the percentage difference of the load repetitions $(\Delta N)$ at higher temperatures from the ones calculated at approximately $14{ }^{\circ} \mathrm{C}$ lower temperatures, the reduction of $\mathrm{N}_{\mathrm{AC}}$ was $93 \%$ at higher temperature, while the reduction of $\mathrm{N}_{\mathrm{FA}}$ was $73 \%$.

Notwithstanding the limited set of data, it can be concluded that the recycled pavement sustains significantly more damage at high temperatures. This effect was more pronounced for the AC overlay. 


\section{Conclusions}

The present research aims to investigate the influence of pavement temperature variations on the bearing capacity of foamed asphalt CIR pavements and therefore to the sustainability of the aforementioned CIR technique. The CIR material is considered as a pavement layer in conjunction and interaction with a relatively thick AC overlay of a heavy-duty pavement structure. It is believed that the present research fills the gap between the temperature sensitivity of the FA material ant its impact on the bearing capacity of the recycled pavement.

For this reason, a field experiment was conducted on a heavy-trafficked CIR pavement (LTPP site), using FWD testing at two periods (i.e., mild and high temperatures).

Based on the analysis results, it can be concluded that the FA material was less sensitive to temperature changes than the AC material. This may be due to the low asphalt content of the FA.

The most critical locations against fatigue failure (i.e., higher tensile strains) in the body of the CIR pavement were found to be at the top as well as at the bottom of the FA layer, confirming past investigations.

An outcome of the present analysis is the estimation of the rate of change of critical strains with respect to temperature fluctuations. The strains induced at the bottom of the FA layer were less sensitive to temperature changes in comparison to the strains at the interface between AC and FA.

The allowable load repetitions of the AC material were much higher than the allowable load repetitions of the FA material $\left(\mathrm{N}_{\mathrm{FA}}\right)$. The differences were more pronounced at mild temperatures than at high temperatures.

The newly constructed layers (AC and FA) sustained significantly more damage from traffic loads at higher temperatures. This was more pronounced regarding the damage of the AC overlay, and it should be considered during the pavement design for application in cases of high temperatures.

The results of the in-situ estimation of the rate of change of critical strains with respect to temperature fluctuations are only valid for the specific CIR pavement section. In order to further improve the quality of the results, it is suggested to conduct NDTs at a wider temperature fluctuation range and to use different software for evaluation of the analyses.

Moreover, in order to contribute towards the influence of the pavement temperature variation towards the sustainability of the FA technique, continuous field monitoring is needed.

Author Contributions: Conceptualization, A.L. and V.P.; methodology, A.L. and V.P.; software, V.P.; validation, A.L.; formal analysis, V.P.; investigation, A.L. and V.P.; resources, A.L.; data curation, V.P.; writing-original draft preparation, V.P.; writing-review and editing, A.L.; visualization, V.P.; supervision, A.L.; project administration, A.L.; funding acquisition, A.L. All authors have read and agreed to the published version of the manuscript.

Funding: Research Council of Laboratory of Pavement Engineering of NTUA.

Institutional Review Board Statement: Not applicable.

Informed Consent Statement: Not applicable.

Data Availability Statement: Not applicable.

Conflicts of Interest: The authors declare no conflict of interest.

\section{References}

1. Van Dam, T.; Harvey, J.; Muench, S.; Smith, K.; Snyder, M.; Al-Qadi, I.; Ozer, H.; Meijer, J.; Ram, P.; Roesler, J.; et al. Towards Sustainable Pavement Systems: A Reference Document. In US Department of Transportation, Federal Highway Administration; FHWA-HIF-15-002; Applied Pavement Technology, Inc.: Urbana, IL, USA, 2015.

2. Miller, T.D.; Bahia, H.U. Establishing a framework for analyzing asphalt pavement sustainability. Int. J. Pavement Res. Technol. 2010, 3, 149-155. 
3. Milad, A.; Taib, A.; Ahmeda, A.G.F.; Solla, M.; Yusoff, M.N.I.M. A review of the use of reclaimed asphalt pavement for road paving applications. J. Teknol. (Sci. Eng.) 2020, 82, 35-44. [CrossRef]

4. Van de Ven, M.F.C.; Molenaar, A.A.A.; Sluer, B.W. Low energy asphalt mixtures for sustainable and durable pavement solutions In Proceedings of the 10th Conference on Asphalt Pavements for Southern Africa, KwaZulu-Natal, South Africa, 11-14 September 2011.

5. Skotnicki, L.; Kuzniewski, J.; Szydlo, A. Stiffness Identification of Foamed Asphalt Mixtures with Cement, Evaluated in Laboratory and In Situ in Road Pavements. Materials 2020, 13, 1128. [CrossRef] [PubMed]

6. Alkins, A.E.; Lane, B.; Kazimierowski, T. Sustainable pavements-Environmental, economic and social benefits of in-situ pavement recycling. In Proceedings of the 87th Annual Meeting, Transportation Research Board, Washington DC, USA, 13-17 January 2008.

7. Jenkins, K.J. Moderator's report: Cold mix technology. In Proceedings of the 8th Conference on Asphalt Pavements for Southern Africa (CAPSA), Sun City, South Africa, 12-16 September 2004.

8. Saleh, A.; Gáspár, L. Advantages and limitations of using foamed bitumen. Acta Tech. Jaurinensis 2021, 14, 300-314. [CrossRef]

9. Losa, M.; Bacci, R.; Axerio, A.T.; Leandri, P. Design of pavements containing foamed bitumen recycled layers. In Proceedings of the 8th International Conference on the Bearing Capacity of Roads, Railways and Airfields, University of Illinois at UrbanaChampaign, Champaign, IL, USA, 29 June -2 July 2009.

10. Schwartz, C.W.; Khosravifar, S. Design and Evaluation of Foamed Asphalt Base Materials; Draft Final Report, Project SP909B4E; Maryland State Highway Administration: Maryland, MD, USA, 2013.

11. Papavasiliou, V.; Loizos, A. Field performance and fatigue characteristics of recycled pavement materials treated with foamed asphalt. Constr. Build. Mater. 2013, 48, 677-684. [CrossRef]

12. Loizos, A.; Papavasiliou, V.; Plati, C. The influence of the AC overlay on the performance of foamed asphalt recycled pavements. In Proceedings of the 3rd International Conference on Transportation Infrastructure (ICTI), Pisa, Italy, 22-25 April 2014.

13. Loizos, A.; Papavasiliou, V. In situ characterization of pavement materials stabilized with foamed asphalt and cement. In Proceedings of the International Conference on Advanced Characterization of Pavement and Soil Engineering Materials, Athens, Greece, 20-22 June 2007.

14. Betti, G.; Airey, G.; Jenkins, K.; Marradi, A.; Tebaldi, G. Active fillers' effect on in situ performances of foam bitumen recycled mixtures. Road Mater. Pavement Des. 2016, 18, 281-296. [CrossRef]

15. Loizos, A.; Plati, C.; Papavasiliou, V. Fiber optic sensors for assessing strains in cold in-place recycled pavements. Int. J. Pavement Eng. 2013, 14, 125-133. [CrossRef]

16. Roadscanners. Road Doctor Software: User's Guide; Version 1.1; Roadscanners: Rovaniemi, Finland, 2001.

17. Irwin, L.H. Back-calculation analysis. In Proceedings of the Tutorial at 9th International Conference on Asphalt Pavements, ISAP, Copenhagen, Denmark, 17-22 August 2002.

18. Long-Term Pavement Performance Program Determination of In-Place Elastic Layer Modulus: Backcalculation Methodology and Procedures. Chapter 2. Backcalculation Methodology and Packages. In Federal Highway Administration Research and Technology. Coordinating, Developing, and Delivering Highway Transportation Innovations; Publication Number: FHWA-HRT-15-036; Turner-Fairbank Highway Research Center: McLean, VA, USA, 2015.

19. Von Quintus, H.L.; Simpson, A.L. Backcalculation of Layer Parameters for LTPP Test Sections, Volume II: Layered Elastic Analysis for Flexible and Rigid Pavements; Publication No. FHDA-RD-01-113; Turner-Fairbank Highway Research Center: McLean, VA, USA, 2002.

20. Loizos, A.; Papavasiliou, V.; Plati, C. Investigating in-situ stress-dependent behaviour of foamed asphalt treated pavement materials. Road Mater. Pavements Des. 2012, 13, 678-690. [CrossRef]

21. BISAR User Manual; Hibbitt, Bitumen Business Group: Singapore, 1998.

22. Huang, Y.H. Pavement Analysis and Design; University of Kentucky: Upper Saddle River, NJ, USA, 2004.

23. Loizos, A.; Papavasiliou, V.; Plati, C. Early life performance of cold-in place pavement recycling using the foamed asphalt technique. Transp. Res. Rec. J. Transp. Res. Board 2007, 1, 36-43. [CrossRef]

24. Doré, G.; Duplain, G.; Pierre, P. Monitoring mechanical response of in-service pavements using retrofitted fiber optic sensors. In Proceedings of the 9th International Conference on Advanced Characterization of Pavement and Soil Engineering Materials, Athens, Greece, 20-22 June 2007.

25. Dynatest. ELMOD Quick Start Manual; Dynatest: Ballerup, Denmark, 2006.

26. Papavasiliou, V.; Loizos, A. Field behavior of foamed bitumen pavement material. In Proceedings of the 7th International RILEM Symposium on Advanced Testing and Characterization of Bituminous Materials, Rhodes, Greece, 27-29 May 2009.

27. European standard bituminous mixtures. In Test Methods for Hot Mix Asphalt. Part 24: Resistance to Fatigue, EN 12697-24; European Committee for Standardization: Brussels, Belgium, 2004.

28. Molenaar, A.A.A. Prediction of fatigue cracking in asphalt pavements. Transp. Res. Rec. Transp. Res. Board 2007, 1, 155-162. [CrossRef]

29. Wirtgen Cold Recycling Manual; Wirtgen GmbH: Windhagen, Germany, 2004 